\title{
Hans Speidel, die Ulmer „Königsgrenadiere“ und die Entstehung des modernen Krieges 1915-1918
}

\author{
Von Dieter Krüger
}

Der Württemberger Hans Speidel (1897-1984) ${ }^{1}$ und sein Hannoveraner Jahrgangskamerad Adolf Heusinger (1897-1982) waren die militärischen Gründerväter der Bundeswehr. Sie dienten in vier deutschen Armeen - im Kontingentheer des Kaiserreichs, in der Reichswehr, in der Wehrmacht der nationalsozialistischen Diktatur, schließlich in der Bundeswehr. In der NATO bekleideten sie hohe militärische Funktionen. Gerd Schmückle, Landsmann, Bundeswehrgeneral und zuletzt Stellvertretender NATO-Oberbefehlshaber in Europa, betonte in seinem Nekrolog auf Speidel, das Fronterlebnis im Ersten Weltkrieg habe diesen „wohl stark geprägt“, obwohl er nie viel darüber gesprochen habe ${ }^{2}$. Die Geschichte der Operationen auf der taktischen Mikroebene des jungen Truppenoffiziers war nur ein, freilich wesentliches Element der Kriegserfahrung.

Speidel gehörte zu den Kriegsleutnants, die als Jünglinge aus meist gutbürgerlichem Hause direkt von der Schulbank auf die Schlachtfelder zogen. Dort vollendete sich ihre Sozialisation. Sein Bruder Wilhelm (1895-1970) gehörte dem 5. Württembergischen Grenadierregiment Nr.123 „König Karl“, den „Königsgrenadieren“, bereits über ein Jahr als Offizieranwärter an, als sich auch Hans Speidel im November 1914 hier bewarb. Die Herkunft der Brüder war idealtypisch (Abb.1). Das Beamtentum stellte etwa $40 \%$ der Militärelite; darunter waren die Forstbeamtenfamilien - der Vater war höherer Forstbeamter - überproportional stark vertreten ${ }^{3}$. Der 17-jährige stand unter dem Eindruck des Begeisterungstaumels, den die Kriegserklärung vom 31. Juli 1914 namentlich in der bürgerlichen

1 Vgl. Dieter Krüger, Speidel, Hans, in: NDB, Bd.24, Berlin 2010, S. 648 f. - Für zahlreiche wertvolle Hinweise danke ich meinen Potsdamer Kollegen Drs. Markus Pöhlmann und besonders Christian Stachelbeck.

2 Gerd SchмüскLe, Ein bedeutender Soldat. Zum Tode Hans Speidels, in: Frankfurter Allgemeine Zeitung, Nr. 270, 29.11.1984.

3 Vgl. Reinhard Stumpf, Die Wehrmacht-Elite. Rang- und Herkunftsstruktur der deutschen Generale und Admirale, Boppard a. Rh. 1982, S. 215 f., 234, 263. 
[Die Abbildung kann aus rechtlichen Gründen online nicht bereitgestellt werden.]

\begin{abstract}
Abb. 1: Die Familie Speidel im Ersten Weltkrieg (vorne vor Haus, von links nach rechts: Schwester Lotte, Vater Emil, Mutter Amalie, Bruder Wilhelm)

(Vorlage: privat).
\end{abstract}

Jugend ausgelöst hatte ${ }^{4}$. Noch in hohem Alter teilte er mit seinem Freund Carl Zuckmayer die Erinnerung an das euphorische "Augusterlebnis“5. Vom 18. bis 20. November 1914 legte Speidel wenige Wochen nach seinem 17. Geburtstag die „Notreifeprüfung“" $a b^{6}$. Am 30. November 1914 rückte Speidel ein ${ }^{7}$. Ohne freiwillige Meldung wäre er erst 1916 einberufen worden ${ }^{8}$.

\title{
I.
}

Im April 1915 traf der - nach heutigem Verständnis - Kindersoldat bei seinem Regiment an der Front ein. Wie alle Linienregimenter bestand es aus drei Bataillonen mit je knapp 1.100 Angehörigen in vier Kompanien. Dazu kam eine Ma-

${ }^{4}$ Vgl. Enzyklopädie des Ersten Weltkriegs, hg. von Gerhard Hirschfeld u.a. (Jeffrey Verhey), Paderborn 2009, S.357-360; Sönke Neitzel, Weltkrieg und Revolution 1914-1918/19 (2008), Bonn 2011, S. 27-30.

5 Vgl. Carl Zuckmayer, Als wär's ein Stück von mir. Horen der Freundschaft, Frankfurt a.M. 2006 (Erstausgabe 1966), S.233-251; Hans Speidel, Aus unserer Zeit, Berlin u.a. 1977, S. 19-21.

${ }^{6}$ Universitätsarchiv Tübingen, 131/986, Reifeprüfung, Kgl. Eberhard-Ludwigs-Gymnasium, 24.11.1914.

7 Vgl. Speidel (wie Anm.5) S.22f.

8 Vgl. Ernst von Wrisberg u. a., Die Organisation der Kriegführung, Teil 1: Die für den Kampf unmittelbar arbeitenden Organisationen (Der Weltkampf um Ehre und Recht, Bd.6), Leipzig 1921, S. 26. 
schinengewehrkompanie pro Regiment, ab 1916 eine pro Bataillon ${ }^{9}$. Die Königsgrenadiere waren im August 1914 mit der 27. Infanteriedivision im Verband des XIII. Armeekorps bis an den Südabhang der Argonnen vorgestoßen. Dort fraß sich der Angriff fest. Am 12. September 1914 erging der Befehl zum Rückzug ${ }^{10}$. Der Plan, nach einer raschen Umfassungsbewegung im Westen sich dem russischen Gegner im Osten zuzuwenden, war am 9. September 1914 in der Schlacht an der Marne gescheitert ${ }^{11}$.

Anfang Oktober 1914 war das Regiment in den nördlichen Argonnen, einem dichten Waldgebiet westlich von Verdun, zum Stellungskrieg übergegangen. Jetzt wurde um einzelne Positionen des Grabensystems gerungen. Die Deutschen wollten die Bahnlinie aus der Festung Verdun nach Westen unter Druck halten. Mit dem Stellungskrieg - eine Art Festungskrieg - schlug die Stunde der Pioniere und der Artilleristen. Letztere hatten ihren meist indirekten Feuerkampf eng mit der Infanterie abzustimmen. Dabei war die französische Feldartillerie (leichte Artillerie) der deutschen zunächst hinsichtlich Feuergeschwindigkeit, Feuerkraft und Munitionsreserven überlegen. Bei den schweren Steilfeuergeschützen waren die Deutschen im Vorteil. Die Kavallerie hatte ihre Bedeutung an der Westfront eingebüßt. Die Aufklärung übernahmen jetzt die Luftstreitkräfte ${ }^{12}$.

Am 29. Januar 1915 gelang es dem Regiment, den Gegner aus dessen vorderen Stellungen im Wald zwischen Binarville und La Harazée zu vertreiben. Es setze sich dort fest, um den nächsten Vorstoß vorzubereiten ${ }^{13}$. Im Mai 1915 wurde Speidel als Gruppenführer in der 2. Kompanie des Regiments verwendet, das Annäherungsgräben (Sappen) auf bis zu 80 Meter vor den Stellungen des Gegners vorantrieb ${ }^{14}$.

9 Vgl. Hermann Cron, Geschichte des Deutschen Heeres im Weltkriege 1914-1918, Berlin 1937, S.116; Otto von Moser, Die Württemberger im Weltkrieg, Stuttgart 1927, S. $112,128 f$.

10 Vgl. Richard Bechtle, Die Ulmer Grenadiere an der Westfront. Geschichte des Grenadier-Regiments König Karl (5. Württ.) Nr.123 im Weltkrieg 1914-1918 (Die württembergischen Regimenter im Weltkrieg 1914-1918, Bd.6), Stuttgart 1920, S.4-27; Moser (wie Anm. 9) S. 19-26, 196-203, 212 f., 215f., 237-242, 282-284.

11 Vgl. Holger H. Herwig, Marne 1914. Eine Schlacht, die die Weltveränderte?, Paderborn 2016; NeitZel (wie Anm. 4) S. 31-45.

12 Vgl. The Cambridge History of the First World War, ed. by Jay Winter, 3 Vols., Cambridge 2014, Bd.1, S.65-71; Christoph NüBEL, Durchhalten und Überleben an der Westfront. Raum und Körper im Ersten Weltkrieg, Paderborn 2014, S. 68-78; Cron (wie Anm. 9) S.145-149, 160, 202 f., 206f.; Moser (wie Anm. 9) S. 33 f.

13 Vgl. Argonnen, in: Enzyklopädie (German Werth) (wie Anm.4) S.341; Bechtle (wie Anm. 10) S. 27-40; Moser (wie Anm. 9) S.28, 41.

14 Vgl. HStAS M 411 Bü 655, Kriegstagebuch (künftig: KTB), GrenRgt 123, Mai 1915; Bechtle (wie Anm.10) S.40f. Die Gruppe ist in der Regel die kleinste taktische Einheit. Zur geographischen Orientierung vgl. hier und im Folgenden die aus Moser (wie Anm.9) stammenden Karten unter https://de.wikipedia.org/wiki/Grenadier-Regiment_\%E2\% 80\%9EK\%C3\%B6nig_Karl\%E2\% 80\%9C_(5._W\%C3\%BCrttembergisches)_Nr._123. 
Die Kompanie arbeitete im Wechsel mit der 4. Kompanie an den Sappen und bezog in den Ruhephasen das Bereitschaftslager („Wellblechhausen“). Das unterstreicht den fabrikmäßigen Charakter, den der Krieg jetzt annahm. Allerdings kam es immer wieder zu Feuerüberfällen durch die Artillerie des Gegners und zum Beschuss durch seine Infanterie. Die beschädigten Stellungen mussten in Stand gesetzt werden ${ }^{15}$. Vorbereitet wurde ein Angriff auf die französischen Stellungen, der abschnittsweise mit dem Ziel erfolgen sollte, eine Feldbefestigung des Gegners („Cimetièrewerk“) einzunehmen ${ }^{16}$. Der Stellungskrieg löste die Front in einzelne Schwerpunkte auf und selbst in diesen tobte das Gefecht um einige Schlüsselpunkte $e^{17}$.

Am 30. Juni 1915 begann der Angriff im Morgengrauen mit einem mehrstündigen Artilleriefeuer auf die gut ausgebauten französischen Stellungen. Um 8 Uhr 45 stürmten die 3., 4., 5. und 7. Kompanie des Regiments. Wie Speidel in seinen Memoiren beschreibt, kostete der Sturm aus dem Graben in Richtung der feuerspeienden Linien des Gegners große Überwindung. Man müsse weniger Angst haben als der Gegner, so Speidel ${ }^{18}$. Die 2. Kompanie folgte, um an diesem und am nächsten Tag die eroberten französischen Stellungen aufzuräumen und die Verbindungsgräben zu den eigenen Stellungen herzurichten. Mit fünf Toten, drei Schwer- und drei Leichtverwundeten war der Tag für die 2. Kompanie vergleichsweise glimpflich verlaufen. Nach Fortsetzung der Arbeiten am folgenden 1. Juli 1915 wurde der Kompanie für den Nachmittag weiteres Vorgehen befohlen. Heftiges Gewehr- und Maschinengewehrfeuer hielt die Grenadiere jedoch in ihren Gräben fest. Offenkundig konnte - so die Lehre auch aus anderen Operationen seit Ende 1914 - ohne ausreichende Artillerievorbereitung die Feuerkraft der gegnerischen Infanterie nicht hinreichend geschwächt werden. Daher feuerte am folgenden 2. Juli die Artillerie eines ganzen Armeekorps zwei Stunden lang auf den verhältnismäßig schmalen Gefechtsstreifen des Gegners. Allerdings antwortete die französische Artillerie mit zum Teil schweren Kalibern, besonders auf die Zuführungswege der deutschen Infanterie. Das stunden- und bald tagelange auf Geländeabschnitte und -punkte konzentrierte Artilleriefeuer prägte zunehmend den Stellungskrieg und verwandelte die Landschaft in eine Trichterwüste ${ }^{19}$. Am späten Nachmittag sollte auch die 2. Kompanie in vorderer Linie antreten, brach den Versuch nach Verlusten durch heftiges Infanteriefeuer zunächst ab, um wenig später

15 Vgl. HStAS M 411 Bü 809, KTB 2. Kompanie Rgt 123, 10.-27.6.1915.

16 Vgl. HStAS M 411 Bü 656, KTB Rgt 123, Juni-Juli 1915, Anlage 3 (Befehl des XVI. AK, 22.6.1915) und 10 (Abschnittsbefehl RgtKdr v. Lupin, 28.6.1915).

17 Vgl. NüBEL (wie Anm.12) S. 112-119.

18 Das habe er seinen Grenadieren gesagt. Vgl. Speidel (wie Anm. 5) S. 24.

19 Vgl. dazu Christian Stachelbeck, Militärische Effektivität im Ersten Weltkrieg. Die 11. Bayerische Infanteriedivision 1915 bis 1918, Paderborn u.a. 2010, S.68-72; The Cambridge History (wie Anm. 12) S. 205-212; NüBEL (wie Anm.12) S.288-297. 
dann doch zu stürmen. Die Besatzungen der französischen Unterstände („Blockhäuser") gaben teils auf, teils kämpften sie weiter. Die Grenadiere wurden durch gegnerische Baumschützen gezielt unter Feuer genommen, erreichten jedoch die befohlene Ziellinie. Mit ihren Spaten gruben sie sich mühselig in den schwierigen Boden ein. Aber immerhin wurden zwei Maschinengewehre in den Abschnitt der 1. und 2. Kompanie gebracht. Die Schanzarbeiten wurden auch in der Nacht fortgesetzt, um die Verbindungsgräben zu den eigenen Ausgangsstellungen anzulegen. Zehn Tote, zehn Schwerverwundete, 22 Leichtverwundete und acht Vermisste hatte dieser Angriffserfolg gekostet. Immerhin verzichtete der Gegner auf einen Gegenangriff. Am Mittag des folgenden 3. Juli rückte die Kompanie nochmals 200 Meter vor, um dort erneut eine Stellung auszuheben. Am späten Nachmittag wurde sie endlich abgelöst. Auch dieser Tag kostete wieder zwei Tote, zwei Schwerverwundete und 11 Leichtverwundete. Am 4. Juli verlegte die Kompanie rund $15 \mathrm{~km}$ hinter die Front.

Das Regiment hatte die Franzosen 700 m zurückgedrängt und dafür mit 131 Toten und 380 Verwundeten bezahlt. Immerhin hatte es auch 647 Gefangene gemacht. Der Unteroffizier Hans Speidel hatte seine erste Schlacht ohne Blessuren bestanden, im Gegensatz zu seinem Bruder Wilhelm, der am 2. Juli verwundet wurde ${ }^{20}$. Nach einem weiteren Angriff am 8. September 1915 richtete sich das Regiment knapp $1 \mathrm{~km}$ nördlich des Weilers La Harazée in Winterstellungen ein. Die Regimentsgeschichte beschreibt, wie sich im rückwärtigen Frontgebiet neben den Lazaretten und logistischen Stützpunkten auch eine eigene Welt provisorischer Freizeiteinrichtungen aus Schwimmbädern, Sporteinrichtungen, Gärten und Lesehallen entwickelte, die man ungern zurückließ21. Am 19. November 1915, knapp zwei Wochen nach seinem 18. Geburtstag, wurde Speidel rückwirkend zum 30. Januar 1915 zum Leutnant befördert und avancierte zum Zugführer ${ }^{22}$.

II.

Zu Jahresbeginn 1916 rückten die Königsgrenadiere ab. Zwei Jahre sollten sie jetzt nahezu ununterbrochen im „Angelpunkt des Krieges“ in Flandern und an der Somme kämpfen ${ }^{23}$. Speidel war mittlerweile Zugführer in der 1. Kompanie im I. Bataillon des Regiments, sein Bruder Wilhelm Kompanieführer der 3. Kompanie

20 Vgl. HStAS M 411 Bü 809, KTB 2. Kompanie, 1.-4.7.1915 (Zitat) und die teilweise abweichenden Angaben im Gefechtsbericht des Regiments, in: HStAS M 411 Bü 656, KTB Rgt 123, Juni-Juli 2015; Bechtle (wie Anm. 10) S. 41-44; Moser (wie Anm. 9) S. 42, 288 f.

21 Vgl. Bechtle (wie Anm. 10) S. 48-50.

22 Vgl. Bundesarchiv-Militärarchiv, Pers 1 104004, Personalakte Hans Speidel, Hefter 1.

23 Vgl. NüBel (wie Anm. 12) S. 22-24 (Zitat S. 23). 
in demselben Bataillon ${ }^{24}$. Die Grenadiere kamen jetzt in eine gepflegte Kulturlandschaft. Speidel entspannte sich bei Ausflügen zu den Denkmälern in Brügge, Gent und Ostende vom Frontalltag ${ }^{25}$. Das flache Flandern hatte gegenüber den bergigen Argonnen jedoch den Nachteil, dass alle Stellungen unter Wasserdruck standen. In jeder Vertiefung, namentlich in den Schützengräben und Granattrichtern sammelte sich Wasser und Schlamm. Nässe und Kälte setzten den Soldaten bald ebenso zu wie die Waffen des Gegners ${ }^{26}$. Unterstände konnten hier kaum als Stollen, sondern nur als Beton- oder Holzbunker über der Erde angelegt werden. Letztere schützten kaum gegen direkte Treffer. Das Regiment bezog einen $800 \mathrm{~m}$ breiten Gefechtsstreifen etwa $4 \mathrm{~km}$ südöstlich von Ypern rechts des Lyskanals. Der Frontabschnitt blieb nicht lange ruhig. Wilhelm Speidel wurde im Februar 1916 erneut verwundet und verließ das Regiment. Es war Soldatenglück, dass die Grenadiere in die Armeereserve abgezogen worden waren, als es zu heftigen Kämpfen auf ihrem Frontabschnitt kam² ${ }^{27}$

Am 21. Februar 1916 rückte das Regiment jedoch mit seiner 4. Kompanie in eine rechts des Kanals gelegene „Kanalbastion“ ein. Es handelte sich um eine 20 bis $30 \mathrm{~m}$ hohe, und etwa $100 \mathrm{~m}$ breite Aufschüttung, welche die Deutschen in der Nacht zum 22. Februar mittels Minensprengung in die Luft jagten und damit die britische Besatzung vernichteten. Schlüsselstellungen des Gegners zu unterminieren und zu sprengen oder aufgeklärte Minenvorbereitungen des Gegners durch Gegenminen zu vereiteln, prägten den zum Repertoire des Festungskrieges gehörenden Minenkrieg ${ }^{28}$. In den Sprengtrichtern wurden oft Infanteriestellungen gebaut. Tatsächlich setzten sich die Briten in dem entstandenen Krater wieder fest. Die Bastion fiel daher nur zum Teil in deutsche Hand; der Versuch die Stellung auszubauen, scheiterte im britischen Artilleriefeuer. Rechts der Bastion lagen weitere Kompanien, darunter die 1. des Leutnants Speidel. „Bastionskommandant“ war zumindest am 25. Februar ein anderer Kriegsleutnant des I. Bataillons aus bildungsbürgerlichem Haus: Wilhelm Hohl aus Ravensburg, ein Jahr älter als Speidel.

Die Grenadiere bauten unermüdlich ihre Stellungen und Verbindungswege aus und sorgten sich um deren Entwässerung, derweil sie der Gegner immer wieder unter Feuer nahm. Auch das Bereitschaftslager wurde zum Leidwesen der Soldaten beschossen. Britische, an Land installierte 38-cm-Schiffsartillerie beteiligte sich am Bombardement. Die Briten setzten zudem zahlreiche Flieger zur Leitung des Artilleriefeuers ein. Am 28. Februar kreisten bis zu neun britische Flieger über der 1. Kompanie, gegen die ein einzelnes deutsches Flugzeug nichts ausrichten

24 Vgl. HStAS M 411 Bü 711, KTB, I. Bataillon Rgt 123, Januar 1916.

25 Vgl. Speidel (wie Anm. 5) S. 25

26 Vgl. Nübel (wie Anm.12) S. 33-46, $273 \mathrm{f}$.

27 Vgl. Bechtle (wie Anm.10) S. 57-61; HStAS M 411 Bü 712, KTB I. Batl. Rgt 123, Februar 1916, Anl. 69.

28 Vgl. dazu Enzyklopädie (Markus PöHLmann) (wie Anm.4) S.720-722. 
konnte $^{29}$. Die Deutschen reagierten im Laufe des Jahres 1916 auf die zunehmende Luftunterlegenheit mit der Verstärkung ihrer Jagdflieger ${ }^{30}$.

Am 2. März 1916 begann um 5 Uhr 45 ein Trommelfeuer der britischen Artillerie. Mit größten Kalibern wurde die Kanalbastion beschossen. Die 1. Kompanie hatte am Vortag in das Bereitschaftslager verlegt. Zunächst war nicht sicher, ob es sich um einen der üblichen Feuerüberfälle handelte oder um eine Angriffsvorbereitung. Daher ging nur ein Zug in den Arbeitseinsatz; die beiden anderen Züge machten sich gefechtsbereit. Zwischenzeitlich war es den Briten gelungen, die Bastion zurückzuerobern. Um 8 Uhr 30 wurde der 1 . Kompanie befohlen, die vorderen Stellungen mit Munition zu versorgen und dann ebenfalls in Stellung zu gehen. Gegen Mittag erhielt die Kompanie den Befehl, gemeinsam mit der 3. Kompanie die britische Infanterie wieder aus den von ihr eingenommenen vorderen Stellungen zu werfen und dann weiter Richtung Kanalbastion vorzugehen. Denn im engen Zugangsstollen zur Bastion waren Teile der 6. Kompanie eingeschlossen, die befreit werden sollten. Der ersten deutschen Sturmwelle schlug ein mörderisches Feuer entgegen; die britische Infanterie hatte an der Bastion zahlreiche Maschinengewehre aufgebaut. Angesichts der zu erwartenden Verluste stellte der Kompanieführer den Angriff ein und zog seine Grenadiere weit zurück. Die im Stollen eingeschlossenen deutschen Soldaten hatten sich unterdessen selbst befreit. An ein Vorrücken in halbwegs gedeckten Gräben und Verbindungswegen war nicht mehr zu denken, da die britische Artillerie das Gelände umpflügte. Daher konnte auch keine vordere Verteidigungsstellung mehr bezogen werden. Immerhin vermochte die 1. Kompanie die Einbruchsstelle abzuriegeln, wobei ihre Soldaten teilweise mit Handgranaten vorgingen. Diese waren zur wichtigsten Waffe im Grabenkampf geworden, denn auf kurze Distanz verliehen sie dem Infanteristen größere Feuerkraft als das Gewehr. Mit Einbruch der Nacht endete die Gefechtstätigkeit.

Am Folgetag setzte wieder Infanteriefeuer ein. Aber die Kompanie wurde am Nachmittag abgelöst, um nach einer Ruhe- und Instandsetzungsphase hinter der Front am 5. März erneut am Kanal in Bereitschaft zu gehen. Ein Kampfbataillon in vorderster Linie, ein Bereitschaftsbataillon dahinter und ein weiteres in Ruhestellung war die übliche Aufstellung eines Infanterieregiments. Die Grenadiere der 1. Kompanie brachten Material nach vorn und Tote zurück. Am folgenden Tag gingen sie wieder in Stellung, die jedoch völlig unter Wasser stand, folglich entwässert und hergerichtet werden musste. Die Schlacht war vorbei; die Briten hatten die Bastion und einen kleinen Geländestreifen erobert. Das Regiment verzeichnete

29 Vgl. HStAS M 411 Bü 806, Bl.128-133, KTB, 1. Kompanie, I. Batl. Rgt 123, 21.2.-1.3.1916; Ina SzYmnau, Feldpostbriefe 1914-1918 als Quelle für das individuelle Kriegserlebnis - Biografie und Identitäten in den Kriegsbriefen Wilhelm Hohls, Magisterarbeit Universität Augsburg 2012, S.45; Bechtle (wie Anm.10) S.61-63; Moser (wie Anm. 9) S. 53.

30 Vgl. John H. Morrow Jr., The Great War In The Air. Military Aviation from 1909 to 1921, Washington/London 1993, S. 148-154, 159-175; Cron (wie Anm. 9) S. 205. 
41 Tote, darunter 2 Offiziere, und 170 Verwundete. Von den acht vermissten Offizieren und 313 Mann war wohl ein Teil ebenfalls gefallen ${ }^{31}$. Hohl kritisierte das „Mätzchen“ des Angriffs auf die Kanalbastion, das am Ende nur „große Verluste“ gebracht und den Verlust der „wunderschönen alten Kampfstellung“ gekostet habe $^{32}$. Die Briten hielten an dem anfangs auch von den Deutschen vertretenen Grundsatz fest, einen Einbruch des Gegners in die vorderste Linie über kurz oder lang mit einem Gegenangriff zu beantworten, um Geländeverluste zu vermeiden ${ }^{33}$.

Nach einer Umgruppierung im Frontabschnitt kehrte relative Ruhe ein, was die eine oder andere Unternehmung nicht ausschloss ${ }^{34}$. Durch seine Kommandierung ins Feldrekrutendepot der 27. Division vom 8. April bis 15. Juni $1916^{35}$ verließ Speidel die unmittelbare Feuerzone. Der Personalersatz wurde hier, nach einer mindestens vierwöchigen Grundausbildung in der Heimat, von fronterfahrenen Soldaten mit den Methoden und Anforderungen des Stellungskrieges im spezifischen Einsatzraum vertraut gemacht. Dabei konnten sich die Ausbilder auch von der Front erholen ${ }^{36}$. Nach einem Jahr an der Front und zwei Schlachten gehörte der 18-jährige Leutnant zu den Fronterfahrenen. Die Lage blieb bis in den Hochsommer verhältnismäßig ruhig, und Speidel wurde vom 8. bis 21. Juli 2016 beurlaubt $^{37}$. Möglicherweise zeitigte die Diskrepanz zwischen Front und Heimat ähnliche familiäre Spannungen wie bei Hohl ${ }^{38}$.

Am 24. Juli begann die Verlegung des Regiments an die Somme. Hier fand eine der bedeutendsten Materialschlachten statt. Briten und Franzosen bereiteten auf $60 \mathrm{~km}$ Breite eine Offensive vor. Sie sollte auch die Franzosen bei Verdun entlasten. Hier griffen die Deutschen seit Februar 1916 an, um die Briten zu einer vorschnellen Offensive im Norden zu provozieren und gleichzeitig den Franzosen eine entscheidende Niederlage zu bereiten ${ }^{39}$. Ein tagelanges Artilleriefeuer sollte auch an der Somme den taktischen Nachteil des Angreifers im Stellungskrieg ausgleichen, allerdings um den Preis des Überraschungsmoments. Der Angriff der „an Truppen, Geschützen, Geschossen, Fliegern und Fesselballonen ${ }^{40 “ ~}$ überlegenen Alliierten

31 Vgl. HStAS M 411 Bü 806, Bl. 133-135, KTB, 1. Kompanie, I. Batl. Rgt 123, 21.2.-1.3.1916; Bechtle (wie Anm. 10) S.63-66 mit teilweise abweichenden Angaben.

32 Zit. nach SzYmnau (wie Anm. 29) S. 98

33 Vgl. NüBeL (wie Anm.12) S. 125-128.

34 Vgl. Bechtle (wie Anm. 10) S. $66 \mathrm{f}$.

35 Vgl. HStAS M 411 Bü 714, KTB, I. Batl. Rgt 123, April 1916, Anl. 79; ebd., Bü 715, KTB I. Batl. Rgt 123, Mai 1916; ebd., Bü 716, KTB I. Batl. Rgt 123, Juni 1916, Anl. 85.

36 Vgl. Wrisberg (wie Anm. 8) S.35; Cron (wie Anm. 9) S.120f.; Nübel (wie Anm. 12) S. 103 .

37 Vgl. HStAS M 411 Bü 717, KTB, I. Batl. Rgt 123, Juli 1916, Anl. 88; Bechtle (wie Anm. 10) S. 66-69.

38 Vgl. Szymnau (wie Anm. 29) S. 81.

39 Vgl. dazu die innovative Interpretation von Olaf Jessen, Verdun 1916. Urschlacht des Jahrhunderts, München 2014, besonders S. 25-28, 55-59, 63.

40 Moser (wie Anm. 9) S. 58. 
begann am 1. Juli 1916 mit der Bereitstellung britischer Angriffsformationen. Sie stürmten frontal gegen die vermeintlich weitgehend zerstörten deutschen Stellungen und büßten schon am ersten Tag nahezu 20.000 Tote und über 35.000 Verwundete ein. Aus der geplanten Durchbruchs- wurde bald eine Abnutzungsschlacht wie die zeitgleiche deutsche Offensive bei Verdun. Dabei warteten die Briten am 15. September 1916 erstmals mit einer zügig entwickelten neuen Waffe auf, dem $\operatorname{tank}^{41}$. Um den Preis von fast 419.000 toten und verwundeten britischen Soldaten und Soldaten aus den Dominions - mehr als im gesamten Zweiten Weltkrieg - sowie 204.000 französischen Verlusten hatten die Alliierten am Ende auf $35 \mathrm{~km}$ Breite etwa $10 \mathrm{~km}$ Boden gewonnen ${ }^{42}$.

Die Königsgrenadiere nahmen am 30. Juli 1916 Positionen am Ortsrand des kleinen Dorfes Guillemont ein. Die Stellungen waren durch das unaufhörliche Artilleriefeuer längst zerstört worden. Die Soldaten lagen in einzelnen Trichtern und gruben sich so gut es ging dort ein. Am 8. August 1916 begann nach vierstündigem Trommelfeuer der britische Angriff. Der gegnerische Einbruch konnte jedoch abgeriegelt und etwa 200 Briten konnten gefangengenommen werden. Dennoch griff der Gegner am Folgetag in der Frühe wieder an, um nach erneutem Misserfolg den Angriff auf Guillemont aufzugeben. Jetzt besetzte Speidels I. Bataillon die vordersten Linien nördlich des Dorfes. Am 16. August griffen die Briten erneut mehrmals in dichten Wellen und ihre Offiziere zum Teil zu Pferd den Abschnitt südlich des Dorfes an. Es wurde vom III. Bataillon verteidigt, das von Teilen des II. Bataillons unterstützt wurde. Aus den Naturhöhlen von Combles führte Speidel seine Grenadiere auf einem kaum mehr erkennbaren und von Gefallenen gesäumten Trampelpfad unter schwerstem Beschuss mit schweren Granaten, Schrapnells und Kugelminen in die nur noch aus Trichtern bestehende Kampflinie.

Der Adjutant des II. Bataillons wurde am 18. August so schwer verwundet, dass er durch den Leutnant Hans Speidel ersetzt wurde, wenn auch zunächst nur kommissarisch ${ }^{43}$. Ungefähr zur selben Zeit avancierte Hohl zum Adjutanten des I. Bataillons und kümmerte sich wie Speidel um Personalangelegenheiten, Ausrüstung, Unterkunft und Führung des Kriegstagebuchs ${ }^{44}$. Am 19. August wurde das I. Bataillon angegriffen. Danach wurden die „zu Schlacke ausgebrannten“, oft an der Ruhr - der für den Stellungskrieg typischen Krankheit - leidenden Königs-

41 Vgl. dazu Markus Pöhlmann, Der Panzer und die Mechanisierung des Krieges. Eine deutsche Geschichte 1890 bis 1945, Paderborn 2016, S. 49, 60-65.

42 Vgl. The Battle of the Somme, ed. by Matthias Strohn, Oxford/New York 2016; Neitzel, (wie Anm. 4) S. 53 f., $59 \mathrm{f}$.

43 Vgl. HStAS M 411 Bü 751, KTB, II Batl. II Rgt 123, August 1916; ebd., Bü 718, KTB, I. Batl. Rgt 123, August 1916, Anl. 93; ebd., Bü 752, KTB, II. Batl. Rgt 123, September 1916; ebd, Bü 756, KTB, II. Batl. Rgt 123, Januar 1917; Speidel (wie Anm.5) S. 25.

${ }^{44}$ Vgl. Szymnau (wie Anm. 29) S. 57 f. 
grenadiere durch das Hannoversche Füsilierregiment Nr.73 abgelöst ${ }^{45}$. Diesem gehörte der 21-jährige Leutnant Ernst Jünger an. Ihm sollte Speidel erst 1941 persönlich begegnen. In seinem Erstling „In Stahlgewittern“ beschreibt Jünger die Kämpfe bei Guillemont, die Hohl gut schwäbisch als „Sauerei“ empfand ${ }^{46}$. Im Dezember 1916 war Speidel dauerhaft zum Adjutanten des ab Januar 1917 von Hauptmann Bäßler geführten II. Bataillons aufgerückt, mit dem Speidel eine Lebensfreundschaft verbinden sollte ${ }^{47}$. Damit hatte Speidel die militärische Rolle gefunden, die ihn bis in höchste Dienstgrade begleiten sollte - die des Führergehilfen und rechte Hand des Kommandeurs bzw. Befehlshabers. Erst 1957, im Alter von 60 Jahren wurde Speidel selbst Befehlshaber. Unterdessen fand sich sein Bruder Wilhelm im Januar 1917 als Kompanieführer wieder beim Regiment ein ${ }^{48}$.

Ende August 1916 kehrten die Königsgrenadiere nach Flandern südlich Ypern zurück, nicht weit von der Kanalbastion. Zwar fanden kaum Großereignisse statt. Aber der Ausbau der stets unter hohem Wasserdruck stehenden Stellungen und die Verteidigung der in vorderster Linie liegenden Minentrichter gegen einzelne Handstreichversuche waren gleichwohl mühselig. Bei der deutschen Artillerie machte sich bereits Munitionsmangel bemerkbar. Im November 1916 bezog man wieder an der Somme Stellung, rund $7 \mathrm{~km}$ Luftlinie östlich des im Sommer verteidigten Guillemont bei der Ortschaft Sailly-Saillisel. Auch hier lagen die ausgelaugten Grenadiere in einer Trichterlandschaft voller Wasser, mit wenig Deckung und Unterständen. Unter britischem Artilleriefeuer und von gegnerischen Scharfschützen anvisiert, versuchte man Stellungen zu bauen. Im Januar 1917 verlegte das Regiment im Rahmen der 27. Infanteriedivision nach Valenciennes, wo neue Verfahren der Abwehrschlacht geübt wurden. Die bislang vier Regimenter je Division wurden auf drei reduziert. Im Gegenzug sollte der Divisionskommandeur selbständig das immer komplexere Gefecht aller Waffen in seinem Abschnitt führen. Das lief auf eine Stärkung gegenüber dem Kommandierenden General des Armeekorps hinaus. Angesichts der wachsenden artilleristischen Überlegenheit der Alliierten sollte die Infanterie die starre Verteidigung der vorderen Gräben zugunsten einer elastischen Gefechtsführung aufgeben. Angeschlagene Stellungen wollte man rechtzeitig aufgeben, um sie womöglich durch Stoßtrupps später wieder zurückzugewinnen. An die Stelle der Gewehre der Infanteristen traten nach Möglichkeit Maschinengewehre sowie Minen- und Granatwerfer. So hoffte man, Menschen zu sparen. Folglich wurden jetzt auch die Königsgrenadiere an leichten Maschinenge-

45 Vgl. Bechtle (wie Anm. 10) S. 69-81; Moser (wie Anm. 9) S. 57f. 417-419, 423-425; Nübel (wie Anm.12) S. 52-54; SPeidel (wie Anm. 5) S. 26 f. (Zitat S. 27).

46 Zit. nach Szymnau (wie Anm. 29) S. 101. Vgl. Ernst Jünger, In Stahlgewittern. Historisch-kritische Ausgabe, hg. von Helmuth Kiesel, Bd.1, Stuttgart 2013, S. 207-251, SPEIDEL (wie Anm. 5) S. 26.

47 Wie die Schreiben des Freudenstädter Hoteliers und CDU-Politikers Wilhelm Baessler (1878-1975) aus den 1950er bis 1970er Jahren im Nachlass Speidel (Privathand) belegen.

${ }^{48}$ HStAS M 411 Bü 755, KTB, II. Batl. Rgt 123, Dezember 1916. 
wehren und leichten Minenwerfern ausgebildet. Die Maschinengewehrkompanien bedienten weiter die schweren Maschinengewehre. Tatsächlich war auch bei den württembergischen Verbänden der Personalverschleiß kaum zu übersehen. In der Heimat wurden jetzt Soldaten freigemacht, die nur bedingt fronttauglich waren. Immer öfter griffen die Fronttruppen in ihrer Personalnot auf unzureichend ausgebildete Rekruten zurück. Dagegen waren die Friedensoffiziere, -unteroffiziere und erfahrenen Mannschaften oft gefallen ${ }^{49}$.

\section{III.}

Im Februar 1917 bezog das Regiment den Frontbogen in einem von Granaten zerhackten Waldstück bei Rancourt, wo die Briten während der Somme-Schlacht mehrmals den Durchbruch versucht hatten. Es galt, das Regiment aus diesem Wald herauszulösen und auf die „Siegfried“-Linie zurückzunehmen, ohne dass der Gegner die Gelegenheit für einen Vorstoß nutzte. Die Deutschen wollten in diesem nach topographischen und taktischen Gesichtspunkten optimierten Stellungssystem die nächste Offensive des Gegners abwarten. Zudem konnten durch die Frontverkürzung 13 Divisionen als operative Reserve gewonnen werden. Damit hatten sich die Deutschen von ihrer Fixierung auf die Behauptung des eigenen Raumes zugunsten einer Tiefenverteidigung gelöst. Die Grenadiere hinterließen dem Gegner systematisch „verbrannte Erde“, um ihm das Nachrücken schwer zu machen. Trotz ihrer Risiken verlief die Operation weitgehend problemlos. Das Deutsche Reich war in die strategische Defensive gegangen. Es setzte seine Hoffnung einerseits in den uneingeschränkten U-Boot-Krieg, der die Alliierten ebenso von ihren überseeischen Zufuhren abschneiden sollte wie man selbst durch die Seeblockade abgeschnürt worden war. Andererseits sollte das „Hindenburg-Programm“ in Verbindung mit dem „Gesetz über den Vaterländischen Hilfsdienst“ die wirtschaftlichen und personellen Ressourcen des Reichs umfassend mobilisieren. Beides sollte sich freilich erst 1917/1918 auswirken. Angesichts des vorhersehbaren Kriegseintritts der Vereinigten Staaten plädierte zwar mancher französischer Entscheidungsträger für ein vorläufiges Abwarten. Am Ende entschlossen sich die Alliierten aber erneut zur Offensive ${ }^{50}$.

Die 27. Division hatte, so ihr Kommandeur, mit einer längeren Ausbildungsund Rubephase gerechnet, wurde jedoch angesichts der britischen Vorbereitungen zum Angriff in die Flanke der Siegfriedlinie bei Arras in Flandern in den unerwar-

49 Vgl. Bechtle (wie Anm. 10) S. 81-84,112f.; Cron (wie Anm. 9) S. 130-132, 180-185; Moser (wie Anm. 9) S. 60, 62 f., 74 f., 446f.; Nübel (wie Anm. 12) S. 150-154; STAchelbeck (wie Anm. 19) S. 164-172, 326-333.

50 Vgl. Bechtle (wie Anm.10) S. 88-92, Neitzel (wie Anm.4) S.68f., 101-106, 123-130; NüBel (wie Anm.12) S.128-135; The Cambridge History (wie Anm.12) S.113-119; Szymnau (wie Anm.29) S. 49f., 104. 
tet schnellen Einsatz abberufen. Das Grenadierregiment bezog links der Ortschaft Quéant Richtung Bullecourt einen knapp 1,5 km langen Gefechtsstreifen mit gut ausgebauten Stellungen. Speidels II. Bataillon marschierte am 9. April 1917 mit einer Gefechtsstärke von 768 Mann plus 54 Mann der Maschinengewehrkompanie in den Abschnitt. Es ging dort zunächst in Ruhestellung, während in Richtung Arras bereits stärkstes Artilleriefeuer zu hören war. Am 11. April griffen die Briten am rechten Abschnitt des Regiments nach kurzer schlagartiger Art.[illerie]-Vorbereitung mit 12 Tanks an. Ein Einbruch in die vorderen Linien der Nachbarregimenter wurde durch Gegenstöße und Aufrollen der Gräben, so der Kriegstagebuchführer Speidel, also durch Vorstoß gegen die bereits in die eigenen Gräben eingedrungenen gegnerischen Infanteristen, unter Beteiligung des III. Bataillons des Grenadierregiments, bereinigt.

Wie man sich das „Aufrollen“ eines Grabens vorzustellen hat, schilderte der Divisionskommandeur: Sobald sich der Gegner in den eigenen Stellungen festgesetzt hatte, wurden diese von beiden Seiten planmäßig angegriffen, indem sie sich durch Werfen von Handgranaten von Schulterwebr zu Schulterwebr im Graben den Weg bahnten. M.G.-Feuer verhinderte ein Entweichen des Feindes nach rückwärts und so drängte man allmäblich den Feind in der Mitte eines Grabenstückes wie eine Herde zusammen. Die Handgranaten rissen furchtbare Lücken in die dichten Haufen des Feindes. Es fehlte ihm an Handgranaten zur Gegenwebr und er hat sich schließlich zu Hunderten ergeben. Gefangene englische Offiziere lobten die splendid action der deutschen Soldaten. Und der Divisionskommandeur lobte, wie planmäßig seine Infanteristen die neue Stoßtrupptaktik umgesetzt hätten. Freilich bedurfte auch diese der artilleristischen Unterstützung, indem der Gegner durch Sperrfeuer daran gehindert wurde, durch Zuführung von Reserven den eingeschlossenen Grabenbesatzungen zur Hilfe zu eilen. Die komplexe Koordination der Waffen entsprach dem komplexen Produktionsprozess moderner Industriegesellschaften. Unterdessen bezogen die Kompanien des II. Bataillons rückwärtige Stellungen und hatten folglich auch keine Verluste zu beklagen. Neun gegnerische Tanks und zwei Flugzeuge waren abgeschossen worden ${ }^{51}$.

Im Kriegstagebuch des Regiments wurde über die Erfahrungen mit der Tank-Waffe berichtet. Die Deutschen hatten den Winter 1916/1917 genutzt, um sich auf deren Abwehr einzustellen ${ }^{52}$. Die mächtigen Ungetüme näherten sich im gemächlichen Tempo von 3-4 km/h und waren schon $600 \mathrm{~m}$ vor den Drahthindernissen gut sichtbar, die sie dann auch mühelos niederwalzten. Sie belegten die

51 Vgl. Nachlass Speidel, Divisionskommandeur Heinrich von Maur an König Wilhelm II. von Württemberg, 14.4.1917 (Abschrift) (Zitate). Speidels Unterschrift rechts unten auf der letzten Seite deutet auf ihn als Autor des Berichts. Vgl. auch HStAS M 411 Bü 758, KTB, II. Batl. Rgt 123, 7.-11.4.1917 (Zitat 11.4.17); Bechtle (wie Anm. 10) S. 92 f.; Moser (wie Anm.9) S.515-517. Das Bataillonskriegstagebuch wurde jetzt regelmäßig von Speidel geführt.

52 Vgl. Pöhlmann (wie Anm.41) S.65-68. 
Gräben mit einem Dauerfeuer aus ihren Kanonen und Maschinengewehren. Allerdings zeigte sich bereits jetzt, dass die eigene Infanterie den gleichsam als Rammböcke der gegnerischen Infanterie eingesetzten Tanks nicht hilflos ausgeliefert war. Der Tank sollte kurz vor den eigenen Drahthindernissen aus Maschinengewehren unter konzentrisches Feuer mit - teurer und daher sparsam zu verwendender Stahlkernmunition („K.-Munition“) genommen werden. Es war auf die Schwachstellen wie Vergaser, Treibstoffbehälter und Sehschlitze zu richten, denn frontaler Beschuss brachte angesichts der starken Panzerung nichts. Neben leichten Minenwerfern, die in der Version von 1917 sogar fast waagrecht feuern konnten, erzielten namentlich Feldgeschütze im direkten Schuss die besten Abwehrerfolge. Fuhr der Tank in eine breite Grabenfalle, war er verloren. Das anfängliche Gefübl der Obnmacht wich dem Jubel der Infanterie, als die gegnerischen Tanks in Flammen aufgingen $^{53}$. Immer stärker wurde seit 1916 auch die Luftbedrohung für die deutsche Infanterie. Die britischen Flieger, so schrieb Hohl, seien weit überlegen. Sie griffen Ziele am Boden mit Bomben und Maschinengewehren an und wenn sie irgendwo Bewegung entdecken, spricht die englische Artillerie ein dröhnendes Wort ${ }^{54}$.

Zwischen 18. und 20. April 1917 bezogen die Königsgrenadiere einen weiter nördlich gelegenen Abschnitt zwischen Bullecourt und Riencourt-les-Cagnicourt (Abb.2). Da sich hier eine Geländeerhöhung mit guter Sicht auf das von den Deutschen besetzte Gelände befand, war mit einem Angriff des Gegners zu rechnen. Er belegte die Stellungen immer wieder mit anhaltendem Artilleriefeuer. Folglich hatten die vorderen Linien nur noch muldenartigen Charakter. Die gelegentlich vom Gegner geschossenen Gasgranaten sollte die „Sisyphusarbeit“55 der Instandsetzung der Stellungen zusätzlich erschweren. Immerhin besaßen die Grenadiere hier meist sichere Betonunterstände. Dazu kam die Bedrohung durch Tiefflieger, welche die deutsche Infanterie auch im rückwärtigen Gebiet der Front immer wieder mit Maschinengewehrfeuer angriffen. Die deutschen Flieger waren ihnen wieder im Verhältnis 1:3 unterlegen ${ }^{56}$. Kein Wunder, dass die Deutschen den Karten eines gefallenen britischen Offiziers entnehmen konnten, wie umfassend die britischen Flieger den Verlauf der deutschen Stellungen aufgeklärt hatten.

Nach einem ruhigen, sonnigen 2. Mai setzte am 3. Mai der Angriff ein. Nach kurzer, aber heftiger Feuervorbereitung aus allen Kalibern trat die britische Infanterie in mehreren Wellen zum Sturm auf die Grenadiere des I. Bataillons an. Auf

53 Vgl. HStAS M 411 Bü 695, KTB, Rgt 123, Anlagen zum KTB 20.3.-15.5.1917, Anlagen 14 und 15 und dazu Bechtle (wie Anm.10) S. 93 f.; Nübel (wie Anm.12) S.137f.; Pöhlmann (wie Anm.41) S.69f.

${ }^{54}$ Zit. nach Szymnau (wie Anm. 29) S. 47. Vgl. auch Bechtle (wie Anm. 10) S.95f. und Battle of the Somme (James Corum) (wie Anm.42) S. 86-88 zur britischen Luftüberlegenheit an der Somme.

55 So der Bataillonskommandeur Adalbert Prinz von Preußen 1917; zit. nach NüBEL (wie Anm.12) S. 44.

56 Vgl. dazu Cron (wie Anm. 9) S. $208 \mathrm{f}$. 
[Die Abbildung kann aus rechtlichen Gründen online nicht bereitgestellt werden.]

Abb. 2: Leutnant Hans Speidel (rechts, vermutlich in Flandern 1917) (Vorlage: privat).

den Flügeln kam es sogar zu Nahkämpfen mit Bajonetten und Messern. Vergeblich setzten die Briten vor Bullecourt auch wieder Tanks ein. Dennoch brachen sie am linken Flügel des Regiments ein. Alle Zufahrtsstraßen und Ortschaften lagen den ganzen Tag unter dem Fener schwerer und schwerster Kaliber. Zablreiche tieffliegende Flieger waren bis in die Nacht binein über den Stellungen und traten mit Hupensignalen mit der engl. Art. und Infanterie in Verbindung. Das II. Bataillon wurde aus der Reserve aus Villers-lès-Cagnicourt in das hintere Stellungssystem verlegt. Gemeinsam mit dem Sturmtrupp der 27. Division wurden unter Mitwirkung von Teilen des II. Bataillons mehrere Gegenstöße angesetzt. Der Handgranatenkampf dauerte die ganze Nacht. Am Ende hatte der Gegner Teile der vorderen Stellungen des Regiments eingenommen. Die Sturmtruppen wurden aus meist jungen, unverheirateten und risikobereiten Offizieren und Soldaten gebildet. Sie wurden zusätzlich mit Flammenwerfern, Sturmkanonen und Minenwerfern ausgestattet und waren die Speerspitze im Nahkampf ${ }^{57}$.

Am folgenden 4. Mai unternahmen Teile des Bataillons erfolgreiche Gegenstöße. Britische Gegenangriffe, unter anderem mit Flammenwerfern, wurden zunächst

57 Vgl. dazu Ralf Raths, Vom Massensturm zur Stoßtrupptaktik. Die deutsche Landkriegstaktik im Spiegel von Dienstvorschriften und Publizistik 1906 bis 1918, Freiburg 2009, S. 164-169; Cron (wie Anm. 9) S. 125-127; Moser (wie Anm. 9) S.77; Stachelbeck (wie Anm.19) S. $99 \mathrm{f}$. 
abgewiesen. Dann erfolgte in der Mittagszeit ein erneuter Großangriff der Briten. Nicht zuletzt weil den Grenadieren die Handgranaten ausgingen und sie auf ihre Gewehre verwiesen waren, kamen die Briten voran, um schließlich deutschen Gegenstößen wieder weichen zu müssen. Der Mangel an Handgranaten zwang die Grenadiere, einige Geländegewinne wieder preiszugeben. Dagegen war es dem Gegner gelungen, rasch Maschinengewehre, Gewehrgranaten und Minenwerfer nach vorn zu bringen. Daher scheiterte ein massiver deutscher Gegenstoß am späten Abend am starken Feuer englischer Nabkampfwaffen. Der Gegner konnte sich bei Bullecourt festsetzen und bedrohte die deutschen Flanken, derweil die eigene Artillerie erneut Sperrfeuer hinter die Einbruchsstelle legte, um dem Gegner die Zufuhr von frischen Kräften, Munition und Verpflegung in die Einbruchsstelle zu erschweren. Am 5. Mai stellten die Deutschen die Gegenstöße ein. Zwar konnte das Schwinden der deutschen materiellen Ressourcen taktisch letztlich nicht kompensiert werden. Aber die Grenadiere hatten den Schlüsselpunkt Bullecourt behauptet, auf den die Briten es hauptsächlich abgesehen hatten. Am folgenden 6. Mai wurde das Bataillon abgelöst. Allein für das II. Bataillon notierte Speidel an Gefallenen einen Offizier und 25 Mann, an Verwundeten zwei Offiziere und 131 Mann sowie 26 Vermisste; die Mannschaftsgefechtsstärke war um 137 auf 577 abgesunken. Das gesamte Regiment hatte 704 Grenadiere und 17 Offiziere eingebüßt, darunter wieder zahlreiche erfahrene Soldaten ${ }^{58}$.

In seinem Erfahrungsbericht über die Kämpfe bei Bullecourt betonte der Regimentskommandeur Kurt von Lupin die wachsende Bedeutung der Ausstattung der Infanterie mit leichten Maschinengewehren, Granat- und leichten Minenwerfern sowie die Bedeutung von ausreichendem Nachschub an Munition und Getränken für die im Gefecht stehende Truppe. Eher archaisch mutete die Forderung an, ein zuverlässiges System von Meldeläufern zu unterhalten, da die technischen Nachrichtenverbindungen zu anfällig waren. Hier reagierte das Heer mit der Schaffung eigener Nachrichtenabteilungen bei den Divisionen ${ }^{59}$. Nicht einmal der anfängliche Misserfolg der britischen Tanks sprach jedoch gegen die wachsende Technisierung der Landkriegführung. Sie begünstigte in einem Abnutzungskrieg zwangsläufig die Partei mit der qualitativ, aber vor allem quantitativ überlegenen Rüstungsproduktion. Zur Überraschung der Deutschen war es Großbritannien bereits 1916 gelungen, seine anfangs auf die Seestreitkräfte ausgerichtete Rüstungsindustrie rasch auf den exponentiell wachsenden Bedarf der Land- und Luftstreitkräfte umzustellen ${ }^{60}$. Mit dem Tank hatten Briten und Franzosen in kurzer Zeit ein Waffensystem entwickelt, das Feuerkraft und Panzerung mit Bewegung verband.

58 Vgl. HStAS M 411 Bü 758, KTB, II. Batl. Rgt 123, 20.4.-6.5.1917 (Zitat 3.5.1917 und 5.5.1917); Nachlass Speidel, Gefechtsbericht des Regimentskommandeurs von Lupin, 8.5.1917 (Abschrift); Bechtle (wie Anm. 10) S. 96-101; Moser (wie Anm. 9) S. 75, 515-517. 59 Vgl. dazu Moser (wie Anm. 9) S.77; Wrisberg (wie Anm. 8) S.211-214, $218-225$.

60 Vgl. The Cambridge History (wie Anm. 12) S. 90, $104 \mathrm{f}$. 
Es bot die Perspektive, auch ohne tagelanges Trommelfeuer wieder zum Bewegungskrieg übergehen zu können ${ }^{61}$. Wenn Lupin ferner die zu großen Gefechtsstreifen der eigenen Kompanien beklagte, gegen die der Gegner immer neue Sturmwellen anbranden ließ, wurde einmal mehr die wachsende personelle Auszehrung der deutschen Heere deutlich. Lupin empfahl tiefer gestaffelte Stellungssysteme und den Vorrang von getarnten und durch ausreichende Drahthindernisse gesicherten Unterständen gegenüber gut ausgebauten Schützengräben. Denn die in die Erde verlegte Schützenlinie bot aus der Luft gut aufzuklärende Ziele für die gegnerischen Artilleristen. Dagegen stellten kleine Gruppen von Infanteristen, die sich in der Trichterlandschaft bewegten und dem Artilleriefeuer unter Umständen ausweichen konnten, keine lohnenden Ziele dar. Freilich wuchs die Anforderung an selbständiges Handeln der Kleingruppen und ihrer Führer. Dagegen fürchtete die höhere Führung Kontrollverlust und die Neigung der Infanteristen, sich in die Tiefe des Stellungssystems zurückzuziehen ${ }^{62}$.

Die Folgen des verschwenderischen Umgangs mit dem knappen Gut Mensch zeigten sich bei der zeitgleich zum britischen Unternehmen bei Arras am 16. April 1917 eröffneten Offensive der Franzosen in der Champagne. Die Führung verheizte ihre Divisionen in einer Weise, dass sich schließlich die Soldaten in zwei Dritteln der Armee den Angriffsbefehlen in unterschiedlichem Maße widersetzten. Von lokalen Unternehmen abgesehen, beschränkte sich jetzt auch Frankreich auf die Defensive, bis das Eintreffen des amerikanischen Militärs die Waagschale zugunsten der Alliierten senken würde. Dagegen wandte sich der britische Oberbefehlshaber nach dem misslungenen Durchbruchsversuch bei Arras dem nächsten Projekt zu. Er wollte mit einer Offensive in Küstennähe den Deutschen ihre U-Boot-Stützpunkte in Belgien wegnehmen und den Druck auf die deutsche Westfront aufrechterhalten ${ }^{63}$.

Die schwäbischen Grenadiere kehrten zunächst an die Somme zurück. Das II. Bataillon bezog dort eine Vorfeldstellung auf einem Höhenzug vor Gonnelieu bei Banteux. Bei weitgehend ruhiger Gefechtslage sorgten begrenzte Vorstöße ins Niemandsland zwischen den Linien gleichsam für kriegerische „Abwechslung“. Das Einbringen von Gefangenen diente nicht zuletzt der Informationsbeschaffung über den Gegner. Außerdem übte man den Gebrauch der leichten Maschinengewehre, die jetzt in wachsender Zahl an die Infanterie ausgegeben wurden. Am 17. August 1917 war es vorbei mit der relativen Ruhe. Die 27. Division wurde als „Eingreifdivision“ der Gruppe Ypern in den Raum Roeselare ca. 28 km ostnordöst-

61 Vgl. dazu Pöhlmann (wie Anm. 41) S. 57-59.

62 Vgl. Nachlass Speidel, Gefechtsbericht des Regimentskommandeurs von Lupin, 8.5.1917 (Abschrift) und dazu Raths (wie Anm. 57) S. 186-189, 198f., 209; STAchelbeck (wie Anm.19) S. $95 \mathrm{f}$.

63 Vgl. The Cambridge History (wie Anm.12) Bd.1, S.120-124; Flandern, in: Enzyklopädie (John M. Bourne) (wie Anm.4) S.489-494, hier S.492f.; Neitzel (wie Anm.4) S.69-71; Stachelbeck (wie Anm. 19) S.195-197. 
lich von Ypern verlegt. Hier hatten die Briten im Juli 1917 ihre Offensive begonnen, wobei sich „Dauerregen“ als „der wichtigste Verbündete der Deutschen erwies“. Gleichwohl ging der von den Schwaben im Herbst 1916 verteidigte Frontbogen bei Wytschaete nach gewaltigen britischen Minensprengungen verloren. Das Regiment wurde mehrmals hinter der Front hin und her verschoben. Es nahm nicht am Gefecht teil und erlitt gleichwohl den Ausfall von 60 Mann durch Artillerie- und Fliegerbeschuss ${ }^{64}$.

Am 23. August 1917 bezogen die Königsgrenadiere einen schmalen, aber tief gegliederten Gefechtsstreifen westlich vor Passendale in der üblichen wassergefüllten Trichterlandschaft. Das II. Bataillon lag jetzt als Kampfbataillon in vorderster Linie. Dicht gedrängt hockten die Grenadiere in kleinen schlecht belüfteten „Betonklötzle (Grundfläche gegen 7 Quadratmeter, Höhe 1,2 m)“65, derweil der Kamerad auf Posten am mühselig getarnten Eingang Ausschau nach dem Gegner hielt. Ein großer Teil der Soldaten lag jedoch in verschlammten Erdlöchern. Sie waren nicht nur dem Artilleriebeschuss noch stärker ausgesetzt als die Soldaten in den Bunkern, die nur ein Volltreffer ausschalten konnte. Die Maschinengewehre des Gegners nahmen jeden Soldaten unter Feuer, der sich bewegte. Die vorn eingesetzte Infanterie hatte sich vom System der Gräben gelöst, die dem Verteidiger keinen Schutz mehr boten. Stattdessen versuchte man jetzt aus wechselnden Trichterstellungen heraus den stürmenden Gegner unter frontales und Flanken-Feuer zu nehmen. Am 25. August ging das II. Bataillon mit zwei Kompanien in die vordere Linie. Kurz nach Mitternacht setzte britisches Trommelfeuer ein. Im Nachbarregiment griffen die Briten wieder mit Tanks an. Am darauffolgenden Tag besaßen die britischen Flieger erneut die Luftherrschaft über den deutschen Stellungen. Der Schwerpunkt der deutschen Flieger lag im französischen Abschnitt ${ }^{66}$.

Am Vormittag des 27. August begannen schwere britische Kaliber, die aufgeklärten Betonunterstände zu beschießen. Mit sechs Treffern wurde der Gefechtsstand des Kampftruppenkommandeurs (KTK) Baeßler zerstört. Der KTK war in aller Regel der Kommandeur des in den vordersten Linien eingesetzten Bataillons. Nach dem fünften Treffer hatte Bäßler seinen Unterstand in die vordere Linie verlegt. Über die anhaltende Bedeutung solcher gemeinsamer Erlebnisse schrieb Bäßler 20 Jahre später seinem früheren Adjutanten: Unser Leben hing damals an einem Fädchen.- Und stolz dürfen wir dabei unserer braven Offiziere [...] u. unserer Grenadiere gedenken.- Uns zwei hat das große Erleben draußen zusammengekittet [...]. Treue Kameradschaft u. Freundschaft für immer sind das Ergebnis. Was Du mir in der schweren Zeit des Grabenkriegs warst, brauche ich nicht besonders hervorzubeben. Daß $\mathrm{Du}$ in Deiner Person die hoben Tugenden des

${ }^{64}$ Vgl. Bechtle (wie Anm.10) S. 102-108; Neitzel (wie Anm.4) S.71f. (Zitat S.72);

Stachelbeck (wie Anm. 19) S. 197-200; Szymnau (wie Anm.29) S. 50 f.

65 So Hohl. Zitiert nach Szymnau (wie Anm. 29) S. 51.

66 Vgl. dazu Morrow (wie Anm. 30) S.215f., 233-236. 
Soldaten, wie sie ein Moltke, Schlieffen u. Seeckt aufgefaßt wissen wollten, vereinigt hast, beweist Deine bisherige militärische Laufbahn ${ }^{67}$.

Eine andere Bunkerbesatzung hatte weniger Glück. 15 Mann fielen einem Volltreffer zum Opfer. Als sich um 1 Uhr nachmittags kleine britische Gruppen den deutschen Stellungen näherten, schlug ihnen das Vernichtungsfener der deutschen Artillerie und Maschinengewehre entgegen. Um 3 Uhr, so hielt Speidel im Kriegstagebuch fest, setzte dann auf breiter Front Trommelfener von bisher nie gekannter Stärke (auch in der Somme-Schlacht, August 1916 nicht) ein. Gleichzeitig trat die englische Infanterie voll bepackt unter dem Schutz von Nebelbomben zum Sturm an. Die erste feindliche Welle wurde sofort von unserem Infanterie- und M.G.Feuer niedergemäbt. [...] An keiner Stelle gelang es dem Gegner, unsere vorderste Linie zu erreichen. Die tief gestaffelte engl. Infanterie erlitt schwere Verluste, [...]. Auch die zablreichen feindlichen Infanterie-Flieger, die durch M.G.-Fener aus geringer Höbe begleiteten, konnten an dem Mißerfolg nichts ändern. Ein englischer Flieger, der aus 150 Meter Höhe unsere Trichterbesatzung bekämpfte, wurde durch Inf.-Fener [...] heruntergeholt. Er blieb [...] zerschellt liegen. Auch ein erneuter Versuch der Briten am Abend scheiterte. Der abgeschossene Flieger ging auf das Konto der von Wilhelm Speidel geführten 5. Kompanie, die den ganzen Tag in vorderster Linie kämpfte und erhebliche Verluste erlitt. Das „Gepäck“ der britischen Infanterie mag ein Hinweis sein, dass diese ihrerseits mit leichten Maschinengewehren, Gewehrgranaten und Sprengmitteln stürmte. Tatsächlich hatten die Deutschen auch hier eine Entwicklung nachvollzogen, die bei ihren Gegnern längst eingesetzt hatte. Am 28. August 1917 wurde das Bataillon abgelöst. Am Folgetag erholten sich die Grenadiere beim Kinobesuch im rückwärtigen Gebiet von den erlittenen Strapazen ${ }^{68}$. Speidel verzeichnete am 7. September noch eine Mannschaftsstärke des II. Bataillons von $629 \mathrm{Mann}^{69}$. Er selbst wurde am 20. August mit dem heiß begehrten Eisernen Kreuz 1. Klasse ausgezeichnet ${ }^{70}$.

In den kommenden Tagen griff der Gegner nicht mehr an, aber seine Artillerie feuerte ununterbrochen weiter auf die deutschen Stellungen. In der Nacht vom 8. auf den 9. September konnten die Briten auf einer Breite von $500 \mathrm{~m}$ auf dem

67 Nachlass Speidel, Baeßler an Speidel, 31. 8. 1937. Wilhelm Baessler (1878-1975) betrieb später ein Hotel in Freudenstadt und war in den 1950er Jahren Landtagsabgeordneter der CDU. Er korrespondierte bis zu seinem Tode mit Speidel. Dieser war seit 1936 Major im Generalstab der Wehrmacht.

${ }^{68} \mathrm{Zu}$ den motivationsfördernden Gratifikationen jeglicher Art und die Fähigkeit der raschen Umstellung auf Vergnügungen als Merkmal der mentalen Gewöhnung an die existenzielle Ausnahmeerfahrung vgl. STACHELbeck (wie Anm.19) S.312-316, 320-322; Szymnau (wie Anm. 29) S. 103-105.

69 Vgl. HStAS M 411 Bü 760, KTB, II. Batl. Rgt 123, 23.-29. 8. 2017 (Zitat 27. 8.1917); Nachlass Speidel, Gefechtsbericht, 27.8.17; Bechtle (wie Anm.10) S.109-113; Moser (wie Anm. 9) S. 80f.; Stachelbeck (wie Anm.19) S.198-200.

70 Vgl. Personalakte (wie Anm. 22) und dazu Szymnau (wie Anm. 29) S.60-64. 
rechten Rand des Gefechtsstreifens nach mehrstündigem Trommelfeuer nochmals einbrechen, wurden aber wieder zurückgedrängt. In den folgenden Tagen erlitt das II. Bataillon in vorderer Linie wiederum durch Beschuss erhebliche Ausfälle. Wilhelm Speidel wurde am 4. September 1917 erneut leicht verwundet und begab sich Anfang Oktober 1917 ins Lazarett ${ }^{71}$. Das Regiment verlegte zur Auffrischung an die niederländische Grenze, unterdessen die Briten die von den Grenadieren noch gehaltenen deutschen Linien dann doch zurückdrängten.

Speidel wurde am 4. Oktober mit dem Ritterkreuz des Württembergischen Militärverdienstkreuzes ausgezeichnet ${ }^{72}$. Am 10. Oktober 1917 ging es zurück an die Front. Der Wald bei Houthulst war nur noch eine morastige Trichterlandschaft mit Baumstümpfen. Im Turnus ging es immer wieder in die Stellungen und zurück in die Bereitschaft. Am 28. Oktober wurde das II. Bataillon als Kampfbataillon von zwei britischen Bataillonen angegriffen. Die Briten kamen im Morast kaum voran, profitierten jedoch vom weitgehend ausbleibenden Sperrfeuer. Die deutsche Artillerie hatte aufgrund schlechter Sichtverhältnisse die Leuchtsignale der eigenen Infanterie nicht gesehen. Trotz erheblicher Fortschritte blieb die Kommunikation die Achillesferse der Koordination von Artillerie und Infanterie ${ }^{73}$. Dagegen hatten die britischen schweren Kaliber furchtbare Vernichtung in die 7. und 8. Kompanie getragen, deren Grenadiere meist vergeblich versuchten, dem Beschuss auszuweichen. Waffen, Munition und Verpflegung waren oft verschüttet. Die Überlebenden der drei vorderen Kompanien wurden zu zweien zusammengefasst, zumal ein Kompanieführer gefallen und einem weiteren der Fuß weggeschossen worden war. Gleichwohl zwangen die verbliebenen eigenen Maschinengewehre den Gegner, seinen Angriff einzustellen. Der Regimentskommandeur betonte die anhaltende Bedeutung sogar schwerer Maschinengewehre in der vorderen Linie. Trotz einiger kleinerer Gefechte war diese Flandernschlacht vorbei. Die Briten hatten die deutschen U-Boot-Basen nicht erreicht. Das nützte dem Reich nur bedingt. Der anhaltend hohe Munitionsverbrauch der britischen Artillerie zeigte, dass es nicht gelungen war, die Insel von ihren überseeischen Zufuhren abzuschneiden. 332.000 Verlusten der Alliierten standen immerhin noch 217.000 Deutsche gegenüber. Das Regiment verlegte ab dem 10. November in das Oberelsass ${ }^{74}$. Speidel wurde vom 24. November bis zum 14. Dezember 1917 beurlaubt $^{75}$. listen.

71 Vgl. HStAS M 411 Bü 760, KTB, II. Batl. Rgt 123, August-November 2017, Kriegsrang-

72 Vgl. Personalakte (wie Anm. 22).

73 Vgl. dazu Stachelbeck (wie Anm. 19) S. 84-95, 106 f., 116-120, 212-216.

74 Vgl. HStAS M 411 Bü 760, KTB, II. Batl. Rgt 123, 26.-28.10.1917 und Anlage Nr.15: Bericht (des Regimentskommandeurs Lupin) über den englischen Angriff am 28. Oktober 1917 (Abschrift); Nachlass Speidel, Lupin, Erfahrungen, 28.10.2016; Bechtle (wie Anm. 10) S. 116-121; Moser (wie Anm. 9) S. 588f., Stachelbeck (wie Anm. 19) S. 206.

75 Vgl. HStAS M 411 Bü 761, KTB, II. Batl. Rgt 123, November 1917-Februar 1918, Kriegsranglisten. 
Die Württemberger hatten den Ruf, in den Abwehrschlachten länger und effektiver als andere durchzuhalten. Aber das Westheer war „bis in die Knochen ermüdet und in den Nerven schwer erschüttert“. Das erfahrene Stammpersonal schwand dahin: Die Regimenter mussten auf teilweise „zu wenig kriegstüchtigen und zu wenig kampffreudigen Ersatz“ zurückgreifen ${ }^{76}$. Offensiverfolge waren nur noch auf dem Nebenkriegsschauplatz Italien und an der Ostfront möglich. Russland schied zwar nach der Oktoberrevolution 1917 praktisch aus dem Krieg aus. Aber eine Mehrheit des Reichstages aus SPD, Zentrum und Linksliberalen hatte am 19. Juli 1917 einen Verständigungsfrieden gefordert. Sie trug damit der wachsenden Erschöpfung und Kriegsmüdigkeit der Bevölkerung Rechnung. Wollte die Oberste Heeresleitung mit dem Eintreffen der Amerikaner den Abnutzungskrieg nicht verlieren, musste sie die Gunst der Stunde nutzen und mit Reserven aus dem Osten im Westen wieder in die Offensive zu gehen ${ }^{77}$. Hauptmann Bäßler berichtete zu Jahresbeginn 1918, die Soldaten seines Bataillons seien gegen ein Friedensangebot und wünschten die Durchsetzung der maximalen deutschen Kriegsziele: dafür packen's wir nochmals! ${ }^{78}$. Die Königsgrenadiere genossen unterdessen die ruhige Zeit im Elsass, in der sie der Heimat nicht nur geographisch, sondern auch mental näher gerückt waren ${ }^{79}$.

\section{IV.}

Anfang Februar 1918 verlegte das Regiment nach Cambrai. Hier hatten die Briten mit dem massiven und konzentrierten Einsatz ihrer Tanks in Kombination mit Schlachtfliegern am 20. November 1917 einen tiefen Einbruch erzielt. Ein Teil des Geländes ging zehn Tage später wieder an die Deutschen verloren, die mit einer größeren Zahl von Sturmtruppen und Schlachtfliegern um die Abwehrschwerpunkte herum die britischen Artilleriestellungen erreichten und ausschalteten. Mancher deutsche Militär sah sich in der Auffassung bestätigt, dass die Entwicklung eigener Tanks nachrangig sei ${ }^{80}$. Am 20. März 1918 bezogen die Königsgrenadiere als „vorderstes Stoßregiment“ der sogenannten Michael-Offensive mit dem II. und III. Bataillon in erster und dem I. Bataillon in zweiter Linie ihre Ausgangsstellungen westlich und nordwestlich von Honnecourt-sur-Escaut, ca. $15 \mathrm{~km}$

${ }_{76}$ Moser (wie Anm. 9) S. 86.

77 Vgl. The Cambridge History (wie Anm.12) S.145-147; Neitzel (wie Anm.4) S. 76-78, 106-109.

78 Vgl. Nachlass Speidel, Dem Regiment, 13.1.1918 (Abschrift).

79 Bechtle (wie Anm. 10) S.121-123.

80 Vgl. The Cambridge History (wie Anm.12) S.128; Morrow (wie Anm.30) S.218f., 236f.; Pöhlmann (wie Anm.41) S.73-77, 83-92, 119-121. Stachelbeck (wie Anm.19) S. $129 \mathrm{f}$. 
südlich Cambrai ${ }^{81}$. Am 12. März war Speidels Regimentskamerad und Adjutant des I. Bataillons, Hohl, mit Teilen des Bataillonsstabes dem Streufeuer der britischen Artillerie zum Opfer gefallen, noch bevor der Angriff begann ${ }^{82}$.

Am 21. März eröffnete die deutsche Artillerie um 4 Uhr 45 bei Dunkelheit das Trommelfeuer unter Einsatz von Kampfgasgranaten. Mit aufgesetzter Gasmaske rückt das Bataillon ab 8 Uhr 15 an die britischen Stellungen heran. Um 9 Uhr 40 begann der Angriff der Infanterie nach der neuen Doktrin mit den Sturmtruppen als Speerspitzen ${ }^{83}$. Im schneidigen Draufgehen wurden die vorderen britischen Stellungen überrannt, ein Verteidigungsschwerpunkt ausgeschaltet und ein britischer Bataillonsstab gefangen genommen. Dabei hatten einige britische Stellungen kaum Artillerietreffer erhalten. Ein um 12 Uhr einsetzender Gegenangriff der auf Lastkraftwagen antransportierten britischen Infanterie mit Unterstützung von zwei Tanks wurde abgewiesen. Einer davon wurde von der Feldartillerie ausgeschaltet. Da das Regiment wesentlich weiter vorangekommen war als seine seitlichen Nachbarn, drohten Flankenstöße des Gegners. Die beiden Kampfbataillone gingen zurück. Dabei konnten die Sturmspitzen nicht mehr zurückverlegen und wurden vom Gegner aufgerieben. In der Nacht griffen die Briten die beiden Bataillone nicht mehr an, die sich unter Bäßler als Kampftruppenkommandeur zur Verteidigung einrichteten und an den Flanken Unterstützung anderer Regimenter erhielten. Am folgenden Tag kam ein erneuter Angriff am Vormittag vor einem Verteidigungsschwerpunkt des Gegners zum Erliegen. Dieser wurde von der deutschen Artillerie unter Vernichtungsfeuer genommen. Mit unvergleichlichem Schwung stürmen die Grenadiere unter gegnerischem Sperrfeuer vor, als die Briten sich abzusetzen begannen. Sie schalteten die britischen Maschinengewehrstellungen im Nahkampf aus. Um 7 Uhr 45 abends ging das Bataillon weitgehend ungehindert an brennenden Ortschaften und durch eilends verlassene britische Stellungen vor und traf erst $500 \mathrm{~m}$ westlich der Ortschaft Fins, rund $9 \mathrm{~km}$ westlich der Ausgangstellung, auf Maschinengewehrfeuer. Das Bataillon grub sich darauf ein und forderte Artillerieunterstützung an. Am 23. März legte das Bataillon einen Rasttag am Ostausgang von Fins ein und verblieb im rückwärtigen Bereich, während die Einnahme einst aufgegebener Orte wie etwa Guillemont gemeldet wurde. Die erhebliche Beute an Waffen, Munition und Verpflegung war ein weiteres Indiz für die materielle Überlegenheit der Briten. In den folgenden Tagen zog das Regiment über das Schlachtfeld von 1916 an der Somme immer weiter westwärts.

Lupin wurde unterdessen für die Leistungen seines Regiments mit dem Pour le Mérite, dem höchsten Tapferkeitsorden ausgezeichnet. Der 23-jährige Wilhelm

${ }^{81}$ Vgl. Bechtle (wie Anm. 10) S.123-126; Moser (wie Anm.9) S.647f. (Zitat S. 248). Zur Offensive vgl. auch The Cambridge History (wie Anm.12) S.147-150; Neitzel (wie Anm. 4) S.78f.

82 Vgl. Szymnau (wie Anm. 29) S. 51 f., Bechtle (wie Anm. 10) S. 125 f.

83 Vgl. Raths (wie Anm. 57) S. 190-196. 
Speidel übernahm am 27. März die Sturmabteilung der 27. Division ${ }^{84}$. Am 5. April begann um 9 Uhr nach zweistündiger Artillerievorbereitung der Angriff der 27. Division. Den in erster Linie eingesetzten Regimentern und vor allem ihren Sturmtruppen schlug ein so mörderisches Maschinengewehrfeuer entgegen, dass der Angriff eingestellt wurde. Das II. Bataillon war unterdessen nach Aveluy beordert worden, um am Folgetag das III. Bataillon im dortigen Wald abzulösen. Hier war es sofort mit einem britischen Gegenangriff konfrontiert ${ }^{85}$.

Die Oberste Heeresleitung stellte jetzt die Offensive ein. Ihr Konzept, nach vergleichsweise kurzer Artillerievorbereitung die Infanterie schwungvoll und unter Umgehung gegnerischer Verteidigungsschwerpunkte und unter Einsatz der besonderen Sturmtruppen vorgehen zu lassen, schien zunächst aufzugehen. Dann fehlten jedoch leistungsfähige Lastkraftwagen, von Tanks ganz zu schweigen, um die geschlagene Bresche auszunutzen. Die Pferde waren ausgemergelt. Zwar hatten die Alliierten rund 100.000 Soldaten mehr verloren als die Deutschen. Deren Problem notiert die Regimentsgeschichte: Die Königsgrenadiere hatten an den beiden Großkampftagen 21. und 22. März insgesamt 785 Mann eingebüßt. Allein an Gefallenen verzeichnete man 11 Offiziere und 138 Grenadiere und Unteroffiziere. Nicht zuletzt der „frische Ersatz aus der Heimat“ und seine „jugendlichen Führer“ hatten geblutet. Diese Verluste waren nicht mehr zu ersetzen ${ }^{86}$. Was den Fronttruppen jetzt zufloss, waren körperlich unterernährte und unterentwickelte junge Männer sowie „Ausgekämmte“ und Genesene, die „aus der Heimat mehr Friedenssehnsucht als Kriegswilligkeit“ mitbrachten ${ }^{87}$.

Während die Deutschen an anderen Frontabschnitten weitere Offensiven eröffneten, glitt der Krieg für die Grenadiere zurück in die bekannten Bahnen des defensiven Stellungskrieges: häufiges Artilleriefeuer auf den eigenen Stellungen, wechselseitige Handstreiche und Vorstöße, der gleichförmige Rhythmus von Stellungsdienst und Bereitschaft. Am 22. April griffen die Briten erneut nach kurzer Artillerievorbereitung an und wurden blutig abgeschlagen. Vor den Stellungen des II. Bataillons hörte man die ganze Nacht hindurch [...] das Jammern und Stöhnen der Verwundeten. Erst gegen Morgen wurden drei verwundete Briten geborgen. Anschließend verbrachten die Königsgrenadiere eine längere Ruhephase im rückwärtigen Gebiet, die zur Auffüllung mit neuem Personal und zur Ausbildung genutzt wurde. Speidel verzeichnete am 17. Mai eine Gesamtstärke des II. Batail-

84 Vgl. HStAS M 411 Bü 762, KTB, II. Batl. Rgt 123, 20.3-4.4.1918 (Zitate 21.3.1918 und 22.3.1918); ebd., Anlagen: Karte des Vorstoßes vom 22.3.-4.4.1918; Bechtle (wie Anm. 10) S.126-132; Moser (wie Anm. 9) S. 648-652.

${ }^{85}$ Vgl. HStAS M 411 Bü 762, KTB, II. Batl. Rgt 123, 5.-8. 4.1918; Bechtle (wie Anm. 10) S. $133 \mathrm{f}$.

86 Bechtle (wie Anm.10) S.133. Vgl. auch Moser (wie Anm.9) S. 93; Neitzel (wie Anm.4) S.77-79; Nübel (wie Anm.12) S.135f.; Stachelbeck (wie Anm.19) S.130-133 und hier zur „Michael“-Offensive S. 134-147.

87 Moser (wie Anm. 9) S. 99. 
lons von 674 sowie 89 Mann der Maschinengewehrkompanie und zusammen 34 Offizieren $^{88}$.

Das Regiment wurde im Sommer wieder an die Somme verlegt und ging Anfang August 1918 beiderseits der Straße von Bray-sur-Somme nach Corbie in die vordere Linie, die nur noch aus Grabenresten, Schützenlöchern und Maschinengewehrnestern bestand. Am 6. August griff das I. Bataillon begleitet von Pionierstoßtrupps nach kurzer Artillerievorbereitung den überraschten Gegner an. Der Erfolg bei verhältnismäßig geringen eigenen Verlusten lag in der Konsequenz solider Ausbildung und der langen Erholungsphase. Der britische Gegenangriff am Folgetag brachte kaum Erfolge. Dagegen griffen die Briten am 8. August bei dichtem Nebel nach kurzem Trommelfeuer mit sechs Tanks an. Sie tauchten plötzlich vor den deutschen Grenadieren auf, die sich unter diesen Umständen kaum wirkungsvoll zur Wehr setzen konnten. Zudem hatten die Briten die Panzerung gegen Infanteriewaffenbeschuss wirkungsvoll verstärkt. Von der eigenen Artillerie erhielten die Grenadiere wenig Feuerunterstützung, da der Gegner die rückwärtigen Stellungen mit Kampfgas belegt hatte. Wieder kreisten britische Flieger über den Stellungen und griffen die deutsche Infanterie mit Bomben und Maschinengewehren an, von der Leitung des Artilleriefeuers ganz abgesehen. Die deutschen Jagdflieger kämpften zwar mit Bravour, aber der Gegner war ihnen fünffach überlegen ${ }^{89}$. Dem III. Bataillon drohte die Einkesselung durch die auf den Flanken erfolgreichen Gegner. Das am Rande der Auflösung stehende Regiment erhielt erst am Nachmittag Unterstützung. Der 8. Kompanie des II. Bataillons, nur noch 15 Mann stark, gelang noch der Abschuss eines Tanks. Freilich verfügten die vorderen Verbände kaum mehr über Stahlkernmunition zur Tankbekämpfung.

Am Morgen des 9. August stellte sich der Gegner erneut mit acht Tanks in Linie mit Zwischenräumen von 100 bis 150 Metern auf. Den Tanks folgten unmittelbar vier Reihen Begleitinfanterie mit der Aufgabe, den Tank vor der Infanterie des Gegners zu beschützen, der ihr zugleich Deckung bot. Die Tanks fuhren am deutschen Graben entlang, um die Grenadiere unter Maschinengewehr- und Geschützfeuer zu nehmen. Nach einem kurzen Rückzug der Tanks und erneutem Trommelfeuer der Artillerie trat dann die britische Infanterie zum Sturm an. Das III. Bataillon wurde überrannt. Seine Reste fluteten mit dem ebenfalls angeschlagenen II. Bataillon bei heftigem britischem Artilleriefeuer zurück. Die 6. Kompanie meldete an dem Tag allein fünf Tote, elf Verwundete und 15 Vermisste. Kurz vor Mitternacht setzten die Briten ihren Tankangriff ohne Artillerievorbereitung fort, dem die Grenadiere kaum mehr Widerstand entgegensetzen konnten, zumal die mittlerweile eingeführten Tankabwehrgeschütze entweder zerstört oder zurückgezogen worden waren. Nach dem Verlust von vier toten, sechs verwundeten und neun

88 Vgl. HStAS M 411 Bü 762, KTB, II. Batl. Rgt 123, 21.4.-23.5.1918 (Zitat 22.4.1918); Moser (wie Anm. 9) S. 94; Bechtle (wie Anm. 10) S.134-138.

89 Vgl. dazu Cron (wie Anm. 9) S. 211 f.; Morrow (wie Anm. 30) S. 299 f., 305-309. 
vermissten Offizieren sowie 48 toten, 360 verwundeten und 331 vermissten Grenadieren wurden die einst drei Bataillone des Regiments zu zweien zusammengelegt, die jeweils noch über etwa 200 Mann verfügten. Die Grenadiere sollten die Ortschaft Bray halten und gruben sich ein. In den folgenden Tagen wurden die Deutschen immer weiter zurückgedrängt. Die Kompanien des Regiments schmolzen auf ein Minimum zusammen. Die 6. Kompanie löste am 12. August eine Kompanie $\mathrm{ab}$, die nur noch aus fünf Soldaten bestand. Das Tagebuch derselben 6. Kompanie verzeichnete für den 24. August: Anfangs waren noch verschiedene Leute preußischer Regimenter zu seben, bauten aber allmählich alle ab, oft zugweise! Die eigene Kompanie verfügte am 26. August noch über 8 einsatzbereite Männer. Am 28. August wurde das Regiment endlich abgelöst. Es verlegte in den Raum nordöstlich von Verdun, wo sich die Gefechtslage weitgehend beruhigt hatte, und blieb dort bis 28. Oktober 1918, Speidels 21. Geburtstag. Nahezu den gesamten Oktober vertrat Speidel den Regimentsadjutanten. Unterdessen schritt die Ausstattung der Infanterie mit Panzerbüchsen (Tankgewehr M 1918) ebenso voran wie die Umstellung von Teilen der Artillerie auf die Tankabwehr. Zunehmend wurden Tankminen und -fallen angelegt. Der Tank hatte sich mithin auf dem Schlachtfeld etabliert, das nun vom Gefecht der verbundenen Waffen - Artillerie, Infanterie, Tanks und Erdkampfflugzeuge - beherrscht wurde ${ }^{90}$.

Die Landkriegführung hatte damit nicht nur den Entwicklungsstand erreicht, mit dem der Zweite Weltkrieg begonnen wurde. Der exponentiell zunehmenden Feuerkraft des einzelnen Soldaten entsprach die reziprok zunehmende Gewalt, der er sich ausgesetzt sah. Insofern ist die gelegentlich zu lesende Metapher vom „Maschinenkrieg“ irreführend; den Krieg führten und erlitten Menschen. Der Mangel an Menschen war für die Deutschen noch gravierender als der Mangel an Munition und Waffen. Am Ende waren diese Faktoren wichtiger als die vermeintlich oder tatsächlich überlegene englische Taktik im letzten Kriegsjahr ${ }^{91}$. Der koordinierten Offensive der britischen, französischen und amerikanischen Truppen hielten die ausgezehrten Divisionen immer weniger stand.

Die erwähnte Absetzbewegung der preußischen Regimenter könnte zum einen ein Hinweis auf den - in der Forschung umstrittenen - „Militärstreik“ ${ }^{92}$ sein, eben-

90 Vgl. Bechtle (wie Anm. 10) S.138-159; Moser (wie Anm. 9) S. 703-706; PÖhlmann (wie Anm.41) S.79-83, 95-99; HStAS M 411 Bü 814, KTB, 6./II. Batl. Rgt 123, 8.8.-26.8.1918 (Zitat 24.8.1918); ebd., KTB, II. Batl. Rgt 123, September 1918 - Januar 1919, Kriegsrangliste Oktober. Zu den Tanks vgl. NüBEL (wie Anm. 12) S. 138 f.

91 Vgl. dagegen Jonathan Boff, Winning and Losing on the Western Front. The British Third Army and the Defeat of Germany in 1918, Cambridge u.a. 2012, besonders S. 226-251.

${ }_{92}$ Vgl. Wilhelm Deist, Verdeckter Militärstreik im Kriegsjahr 1918?, in: Der Krieg des kleinen Mannes. Eine Militärgeschichte von unten, hg. von Wolfram WeTte, München/ Zürich 1992, S. 146-167 und dazu Wencke Meteling, Ehre, Einheit, Ordnung. Preußische 
so wie das in der Regimentsgeschichte angeführte „Abbröckeln der Leute aus der Gefechtslinie“. Zum anderen kam hier auch ein mit Vorbehalten gegen die „schlappen Preußen“ verknüpftes schwäbisches Selbstbewusstsein zum Tragen ${ }^{93}$. Vor dem Hintergrund des sich abzeichnenden Zusammenbruchs ÖsterreichUngarns und des Osmanischen Reichs seien die Königsgrenadiere mehrheitlich mit dem Waffenstillstandsgesuch der Reichsregierung einverstanden und dennoch weiter bereit, ihre Pflicht zu tun, so Lupin ${ }^{94}$. Es habe „von einer ausgesprochenen Revolutionsstimmung schlechterdings nicht gesprochen werden“ können ${ }^{95}$. Die schon 1917 immer deutlicher spürbare Erosion von Moral, Disziplin und Qualität der deutschen Soldaten beschleunigte sich jedoch. Statt revolutionärer Stimmung verbreitete sich Apathie, „Drückebergerei“ und die Bereitschaft in Gefangenschaft zu gehen. Echte Desertion blieb die Ausnahme ${ }^{96}$. Die letzte Schlacht, die das Grenadierregiment nun gegen die Amerikaner schlug, sprach für den anhaltenden Korpsgeist der Königsgrenadiere ${ }^{97}$.

Das Regiment verlegte durch zurückflutende Einheiten ins Vorfeld der Maas, die als Widerstandslinie aufgebaut wurde. Dem II. Bataillon Speidels fiel die undankbare Aufgabe zu, zwischen Tailly und Villers-devant-Dun das Nachhutgefecht gegen die vordrängenden Amerikaner zu führen, die die Deutschen mit einem Trommelfeuer aus Brisanz- und Gasgranaten belegten und die Lücken in der deutschen Front aufklärten. Das II. Bataillon wurde dem schwer bedrängten 120. Infanterieregiment unterstellt, ebenfalls aus Ulm. Bataillonsadjutant Speidel machte sich am Nachmittag des 1. November 1918 auf, um den neuen Regimentsstab zu suchen und kehrte morgens um 3 Uhr des 2. November wieder zurück. Am Nachmittag desselben Tages stürmten die Amerikaner in dichter Schützenlinie, Welle auf Welle in das Feuer der Grenadiere. Da dem Bataillon nichtsdestotrotz die Umfassung drohte, setzte es sich ohne Probleme vom Gegner ab, um am Folgetag eine Auffangstellung bei Beaufort-en-Argonne zu beziehen. Am 4. November griffen die Amerikaner erneut in dichten Kolonnen an. Die Grenadiere zogen sich weiter zurück, um nun, unter dem Schutz eigenen Artilleriefeuers von jenseits der Maas und vom Gegner nicht mehr verfolgt, den Fluss auf einer Behelfsbrücke westlich Inor zu überschreiten. Anhaltender Regen, unzureichende Verpflegung und die übermenschlichen Anstrengungen der vergangenen Tage hatten den Grenadieren

und französische Städte und ihre Regimenter im Krieg, 1870/71 und 1914-19, Baden-Baden 2010, S. 294-301.

93 So Hohl. Vgl. Szymnau (wie Anm. 29) S. 92-95, 110 (Zitat S. 94).

${ }^{94}$ Nachlass Speidel, Lupin an 53. Infanteriebrigade, 13.10.1918 (Entwurf).

95 So Bechtle (wie Anm. 10) S. 163, 157, der als Hauptmann der Reserve zwischenzeitlich die Führung des zweiten Bataillons übernommen hatte.

96 Vgl. Alexander Watson, Enduring the Great War. Combat, Morale and Collapse in the German and British Armies, 1914-1918, Cambridge 2008, S.184-231; STACHelbeck (wie Anm. 19) S. 296-298, 344-347.

97 Vgl. dazu Meteling (wie Anm. 92) S. 274-282. 
zugesetzt. Aber sie hatten sich an die Hoffnung geklammert, bald hinter die Maas zu gelangen. Während sich die Artilleristen beider Seiten gegenseitig beschossen, grub sich das Regiment am Ostufer ein, wobei ihm kaum mehr Material zum Stellungsbau zur Verfügung stand. Allenthalben zogen sich jetzt die deutschen Soldaten in unzulänglich vorbereitete Stellungen zurück ${ }^{98}$.

Noch am 11. November überschritten die Amerikaner die Maas bei Pouilly. Mit lauter Freude von Allen nahm das Bataillon die Nachricht vom Waffenstillstand ab 11 Uhr 55 vormittags auf. Zu Fuß traten die Königsgrenadiere den langen Marsch in die Heimat an, um am 17. Dezember endlich auf die Eisenbahn verladen $\mathrm{zu}$ werden. Am folgenden 18. Dezember fuhr der Zug, der unterwegs mit Tannengrün und Fabnen geschmückt wurde, unter lautem Jubel und klingendem Spiel in Ulm ein. Hier hielt das Regiment unter dem Geläute der Münsterglocken [...] festlichen Einzug in die reich beflaggte Stadt ${ }^{99}$. Die Regimentsgeschichte berichtet von Reibereien zwischen Offizieren und Mannschaften. Gleichwohl sei „es den Soldatenräten zu verdanken, daß ein Abgleiten in das radikalste Fahrwasser vermieden blieb“ ${ }^{100}$. Der Einzug der Königsgrenadiere schien die Behauptung der Obersten Heeresleitung zu bestätigen, das Heer sei im Felde unbesiegt geblieben. Die Lebenslüge ersparte die bittere Einsicht, dass alle Opfer vergeblich erbracht worden waren, freilich um einen hohen Preis. Erst nach der vollständigen militärischen und moralischen Niederlage 26 Jahre später begriffen die Deutschen, dass ein Krieg gegen eine materiell überlegene Koalition von Industriestaaten selbst dann nicht zu gewinnen war, wenn man den europäischen Kontinent erobert hatte. Die Vorstellung, nicht die politische und militärische Führung des Kaiserreiches, sondern die Politiker der künftigen Republik, die den Waffenstillstand schlossen, seien verantwortlich für die Niederlage, hatte dem Nationalsozialismus den Weg bereitet ${ }^{101}$. Dessen Zusammenbruch überlebte der zum Stabschef einer Heeresgruppe avancierte ehemalige Kriegsleutnant von 1914 um Haaresbreite. Bereits im Dezember 1918 beschlossen die Offiziere des Regiments die Gründung eines Traditionsverbandes. Die Erlebnisgemeinschaft der Königsgrenadiere wurde zur Erinnerungsgemeinschaft. Der jetzt 21-jährige Veteran Speidel blieb ihr zeitlebens verbun$\operatorname{den}^{102}$.

98 Vgl. HStAS M 411 Bü 763, KTB, II. Batl. Rgt 123, 1.-10.11.1918 (Zitate 2.11.1918, 4.11.1918 und 6.11.1918); Bechtle (wie Anm.10) S.159-163; Boff (wie Anm.91) S. $227-229$.

99 Vgl. HStAS M 411 Bü 763, KTB, II. Batl. Rgt 123, 7.11.-19.12.1918 (Zitate 9.11.1918 und 18.12.1918); Bechtle (wie Anm.10) S.164-172; Moser (wie Anm. 9) S. 758 f.

100 Bechtle (wie Anm. 10) S. 167.

101 Vgl. The Cambridge History (wie Anm. 12) S.166-171.

102 Vgl. Nachlass Speidel, Rundschreiben Richard Bechtle, Februar 1919. Material und Korrespondenz zum Traditionsverband und dessen Mitgliedern im Nachlass Speidel erstrecken sich bis 1981. 